\title{
The Influence of Fiber/Matrix Interface Properties on Complementary Energy and Composite Damage Tolerance*
}

\author{
Victor C. $\mathrm{Li}^{1,3}$, T. Kanda ${ }^{2,3}$, and Z. Lin $^{3}$ \\ ${ }^{1}$ Visiting Professor, Hong Kong University of Science and Technology, Hong Kong \\ ${ }^{2}$ Senior Research Engineer, Kajima Corporation, Japan \\ ${ }^{3}$ The ACE-MRL, Department of Civil and Environmental Engineering, University of Michigan, \\ Ann Arbor, MI 48109-2125 USA
}

Keywords: Brittle Matrix Composite, Damage Tolerance, Chemical Bonding, Crack Bridging

\begin{abstract}
This paper reviews recent research on cement based composites design for damage tolerance. Specific focus is placed on the influence of fiber and interface properties on the complementary energy of the composite crack bridging behavior, which in turn governs the mechanics of composite fracture. The theoretical concepts are illustrated with examples of highly damage tolerant cement based composites containing fiber types with and without chemical interfacial bonds. The composite fracture and damage tolerant behaviors are rationalized with the mechanics of steady state cracking in fiber composites.
\end{abstract}

\section{INTRODUCTION}

Damage tolerance is well recognized as an important property for structural materials. The feasibility of designing composites with this desirable property has been suggested. Using double edge notched cement matrix based composites, Li [1] demonstrated that with proper selection of fiber, matrix and interface, notch insensitivity can be achieved. Development of damage tolerant cement based composites have reached a state where structural applications are now being considered. Several preliminary structural component tests have revealed the value of adopting micromechanics approach in composite materials engineering design for enhancing structural performance [2-5].

This paper focuses on the influence of the nature of interfacial bond on composite damage tolerance. The crack bridging behavior and associated complementary energy concept first proposed by Marshall and Cox [6] is used as the linkage between interfacial bond and composite fracture behavior. It is illustrated through theoretical and experimental studies that when the interface is dominated by chemical bond over frictional bond, the complementary energy decreases so that steady state cracking becomes more difficult to attain, thus interrupting composite tensile strain-hardening and damage tolerant response. However, with proper adjustments in other fiber properties, interfaces with high chemical bonding can be rendered benign. Alternatively, by adjusting matrix composition which influences both matrix properties and interface properties, the same fiber can still be used in a composite which shows damage tolerant response.

\footnotetext{
" To appear in Key Engineering Materials: Proceedings, 3rd Conf. on Frac. \& Strength of Solids, Hong Kong, Dec., 1997.
} 
In the following the damage tolerant response for two composites is first reviewed. Theoretical concepts are then applied to relate interface properties to crack bridging behavior and to steady state cracking conditions. The complementary energy and damage tolerant behavior of several composites are then discussed in this theoretical context.

\section{DAMAGE TOLERANT COMPOSITE BEHAVIOR}

It is well known that materials such as cement and concrete are highly notch sensitive. Both materials are brittle with toughness less than $0.1 \mathrm{~kJ} / \mathrm{m}^{2}$. In this section we review the damage tolerant response under indentation loads of a cement based composite reinforced with PolyvinylAlcohol (PVA) fibers, and the damage tolerant response under direct tensile loads of notched specimens of another cement based composite reinforced with high modulus Polyethylene (PE) fibers. Both fibers are in short random form. However the PVA fiber has a high chemical bond with cement. Chemical bond is practically non-existent in the PE fiber/matrix interface, as measured by single fiber pull-out tests. (To distinguish the PVA fiber used in the indentation test from another PVA fiber to be discussed later, we shall call this the PVA-A fiber). The properties of these fibers are detailed in Table 1. These two test results show that with judicious design, it is possible to achieve damage tolerance for both fiber (interface) types. In Sections 3 and 4, however, it is shown that damage tolerant behavior favors interface with low chemical bond in comparison with frictional bond.

Table 1: Properties of Three Fibers Used in This Study

\begin{tabular}{|l|l|l|l|}
\hline & PVA-A & PVA-B & PE \\
\hline Length $\mathbf{L}_{\mathrm{f}}(\mathbf{m m})$ & 12 & 6 & 12.7 \\
\hline Diameter $\mathbf{d}_{\mathrm{f}}(\mathbf{m m})$ & 0.04 & 0.014 & 0.038 \\
\hline Elastic modulus $\mathbf{E}_{\mathrm{f}}(\mathbf{G P a})$ & 21.8 & 60 & 117 \\
\hline Nominal Strength $\sigma_{\mathrm{fu}}(\mathbf{M P a})$ & 806 & 1666 & 2400 \\
\hline
\end{tabular}

Figure 1 shows the indentation test configuration. A circular steel plate is pushed into a slab of the specimen which is supported on its underside on a flat surface. Indentor size includes $67 \mathrm{~mm}$ and $90 \mathrm{~mm}$, besides the $30 \mathrm{~mm}$ indicated. Details can be found in [5]. Two types of specimens are used, a PVA-A composite and a control specimen with plain mortar (cement and sand, but no fiber). For each specimen type, test is repeated with different load area as a ratio of the slab surface area. Figure 2 shows the load deflection curves for the two specimen types. It is clear that the deformation capacity of the composite is significantly enhanced, by as much as an order of magnitude. The failed specimens are shown in Figs. 3 and 4. In Fig. 3, the mortar reflects the typical response of a brittle material under a flat indentor. Radial fracture leads to complete and catastrophic failure of the specimen. In Fig. 4, the composite specimen shows the flat indentor punching in, without fracture of the specimen. A close up (Fig. 4b) image of the specimen reveals microcracks, with average width of $24 \mu \mathrm{m}$ ) at the edge of the punched depression. The material under the indentor appears to undergo 'plastic yielding', suggesting a very high damage tolerance of this brittle matrix composite. 


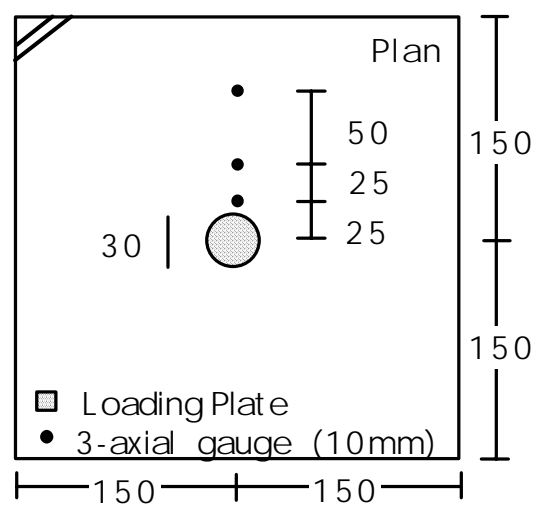

Fig. 1: Indentation Test Configuration

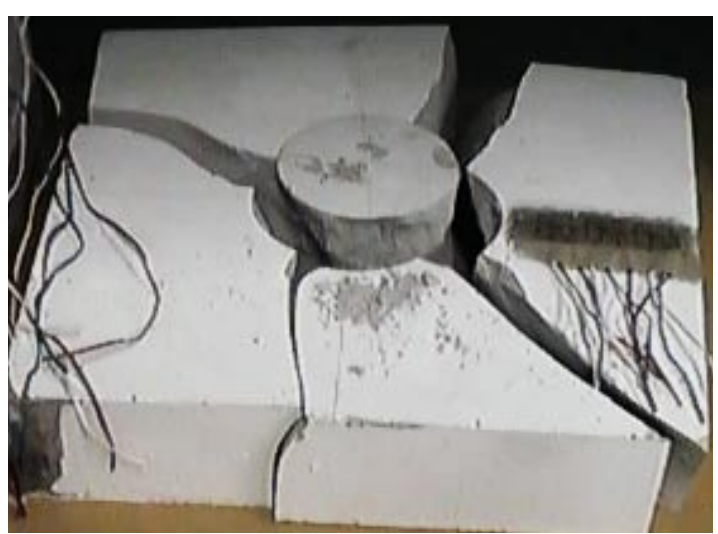

Fig. 3: Failed Mortar Specimen

For uniaxial tensile tests, both notched and unnotched specimens of PE reinforced composites are tested. Test details can be found in [7]. The tensile load deformation curves of these plates (Fig. 5) show extensive inelastic straining for both notched and unnotched specimens. U-3 and U-7 have notch lengths of $15 \mathrm{~mm}$, while U-4 and U-8 have notch lengths of $20 \mathrm{~mm}$. U-28 is unnotched. The peak load is plotted as a function of the reduced section of the notched specimens in Fig. 6 which also shows the linear reduction line for constant strength. The data of the notched specimen lying near (and actually slightly above) this line suggests that these composites are notchinsensitive. The surface of the notched specimen (Fig. 7) shows multiple cracks typical of strain hardening fiber reinforced composites. Although the ultimate localized fracture is in the reduced section, multiple cracking spreads along the full length of the specimens prior to final failure.

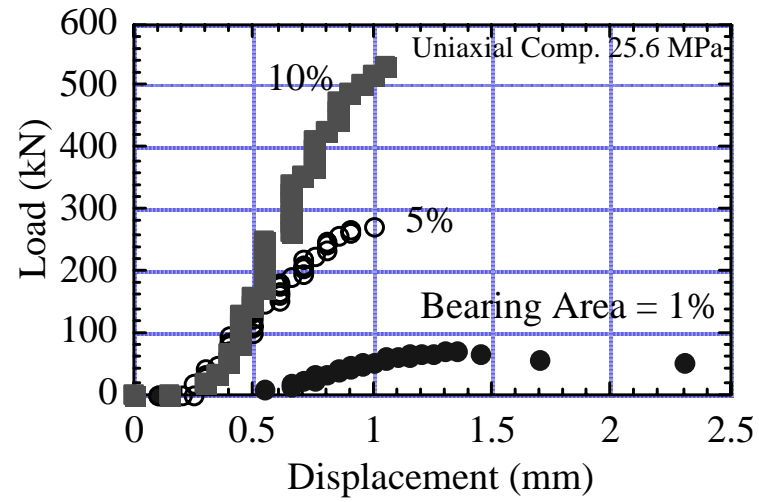

(a)

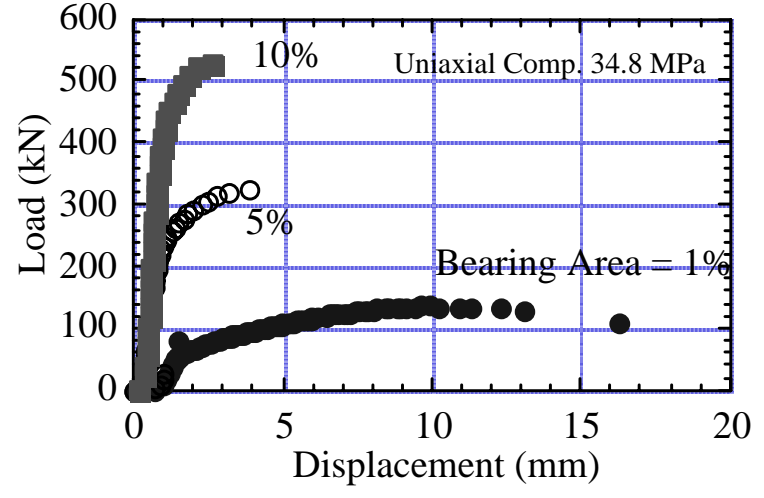

(b)

Fig. 2: Load-deflection Curves of Indentation Tests For (a) Mortar, and (b) PVA-A Composites 


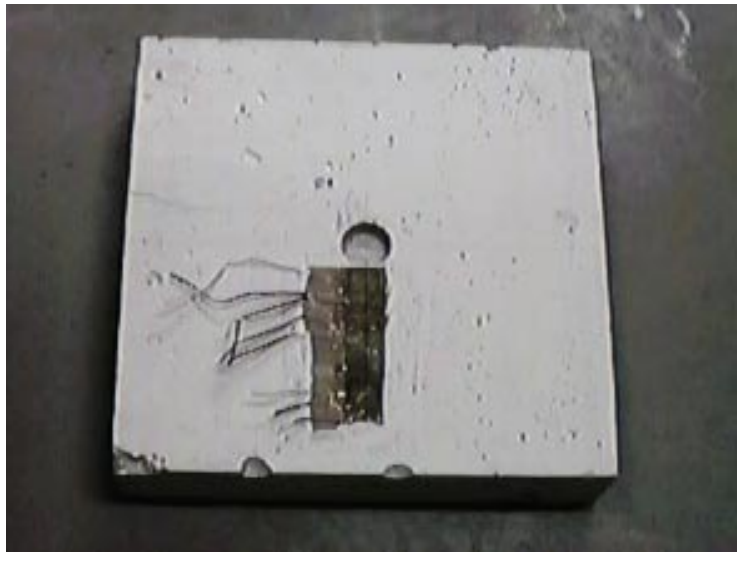

(a)

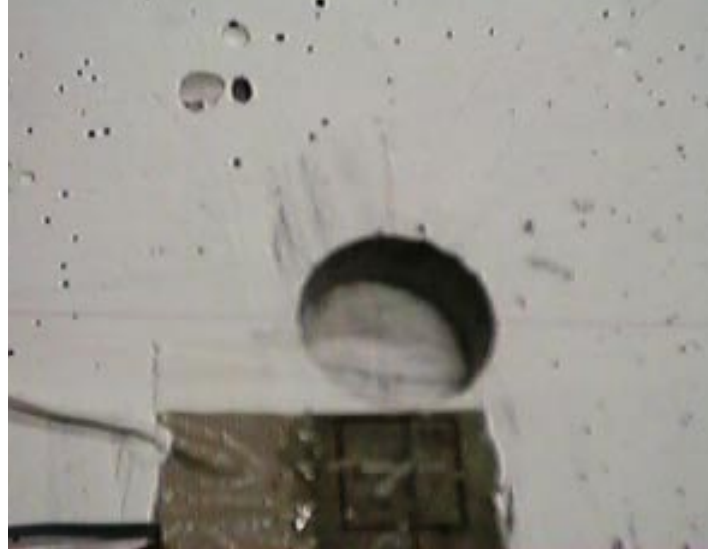

(b)

Fig. 4: Failed PVA-A Specimen (a) Whole Specimen, and (b) Close-Up of Specimen Near Indentor.

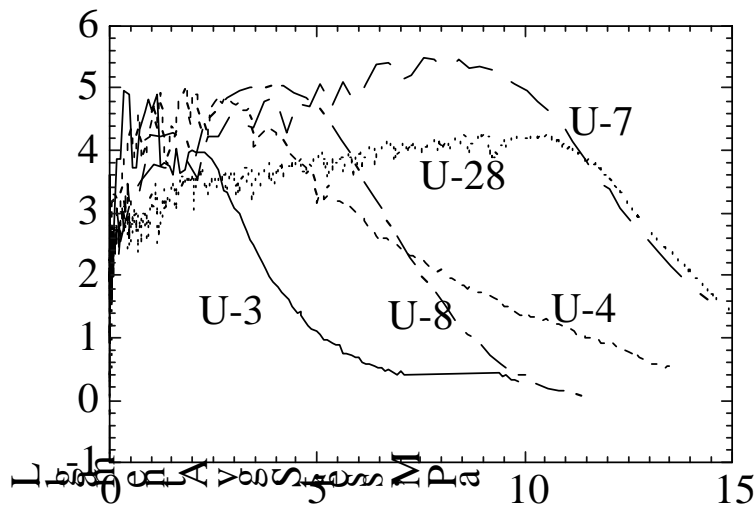

Displacement, $\mathrm{mm}$

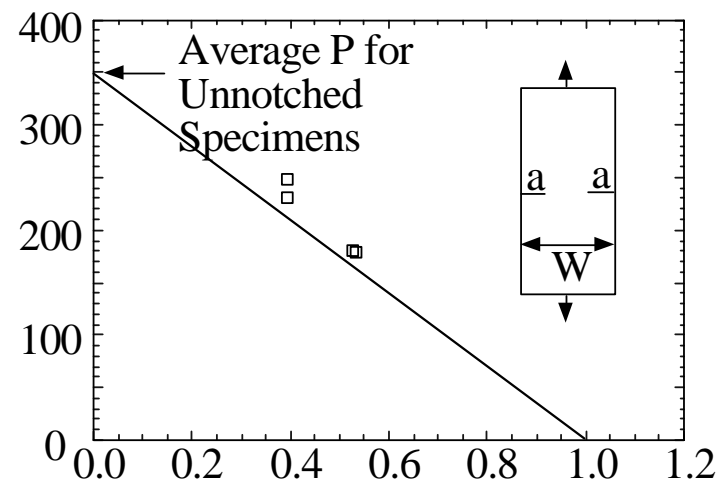

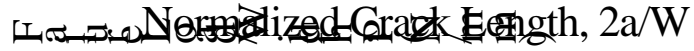

Fig. 5: Load Deformation Curves of PE-Composites
Fig. 6: Maximum Load for Specimens with Different Notched Depths

\section{THEORETICAL CONCEPTS}


The fracture behavior of a deeply notched specimen of a strain-hardening composite has been examined experimentally [7,8] and theoretically by Li [1]. The FEM analysis is based on constitutive relations [9] embodying the uniaxial tensile strain-hardening response of these composites and generalized to multi-axial response. Analysis results show that extensive damage development envelops the classical fiber bridging zone on the main crack plane prior to true crack extension, resulting in toughness in excess of $25 \mathrm{~kJ} / \mathrm{m}^{2}$ [7]. This response must be responsible for the damage tolerant behavior observed and briefly described in Section 2 above. This implies that tensile strain-hardening manifested from multiple matrix cracking is necessary for damage tolerant design.

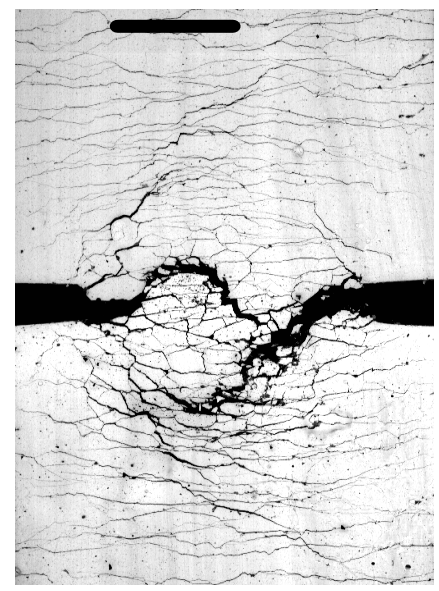

Fig. 7: Damage Pattern of a Double-Edged-Notched Specimen of an ECC. Top marker is $20 \mathrm{~mm}$.

The concept of multiple cracking in fiber reinforced brittle matrix composites has been extensively studied, starting with the investigation of fiber reinforced cement by Aveston et al [10]. Marshall and Cox [6] proposed a simple means of determining the condition for steady state crack extension, required for multiple cracking. Based on a J-integral analysis, the condition can be written in terms of the complementary energy $\mathrm{C}$ and the crack tip toughness $\mathrm{J}_{\mathrm{o}}$ :

$$
C \geq J_{o}
$$

where $C$ is defined in terms of fiber bridging property via the $\sigma-\delta$ curve:

$$
C=\sigma_{o} \delta_{o}-\int_{0}^{\delta_{o}} \sigma(\delta) d \delta
$$

and $\sigma_{\mathrm{o}}$ and $\delta_{\mathrm{o}}$ are the maximum bridging stress and the corresponding crack opening. Graphically, $\mathrm{C}$ is simply the complementary area to the left of the $\sigma-\delta$ relation up to peak stress. Equation (1) suggests that damage tolerant behavior prefers a $\sigma-\delta$ relation with large complementary energy or area. For short random fibers in which the fiber pull out against interfacial friction, close form analytic expression is available for the $\sigma-\delta$ curve in terms of fiber and interface properties [11]: 


$$
\sigma(\delta)= \begin{cases}\sigma_{o}\left[2\left(\delta / \delta_{o}\right)^{1 / 2}-\left(\delta / \delta_{o}\right)\right] & \text { for } \delta \leq \delta_{o} \\ \sigma_{o}\left(1-2 \delta / L_{f}\right)^{2} & \text { for } \delta_{o} \leq \delta \leq L_{f} / 2 \\ 0 & \text { for } L_{f} / 2 \leq \delta\end{cases}
$$

where $\sigma_{o}=\frac{1}{2} g \tau V_{f} \frac{L_{f}}{d_{f}} ; \delta_{o}=\frac{\tau L_{f}^{2}}{E_{f} d_{f}(1+\eta)}$. In Eqs. (3) $V_{f}, L_{f}, d_{f}$, and $E_{f}$ are the fiber volume fraction, length, diameter and Young's Modulus, respectively. $\tau$ is the fiber/matrix frictional bond strength, and the snubbing factor $g$ is related to a snubbing coefficient $\mathrm{f}$ [3] associated with the effect of inclined fiber pull-out analogous to rope over a friction pulley. Finally, $\eta=$ $\left(V_{f} E_{f}\right) /\left(V_{m} E_{m}\right)$, where $V_{m}$ and $E_{m}$ are the matrix volume fraction and Young's Modulus, respectively.

For fiber/matrix interface chemically bonded, interfacial fracture energy needs to be overcome for debonding. In addition, when bonding is strong, fibers may rupture in the crack opening process. The presence of chemical bond and plausibility of fiber rupture alters the $\sigma-\delta$ relation from that of Eq. 3. For this case, an analytic model has been constructed [12]. However, simple close form analytic expression for the complementary energy is not available. It is computed numerically.

The influence of chemical bond strength on the shape of the $\sigma-\delta$ relations is schematically illustrated in Fig. 8. This figure reveals the negative effect of chemical interfacial bond on damage tolerance, since it raises the starting point of the $\sigma-\delta$ curve and reduces the complementary energy.

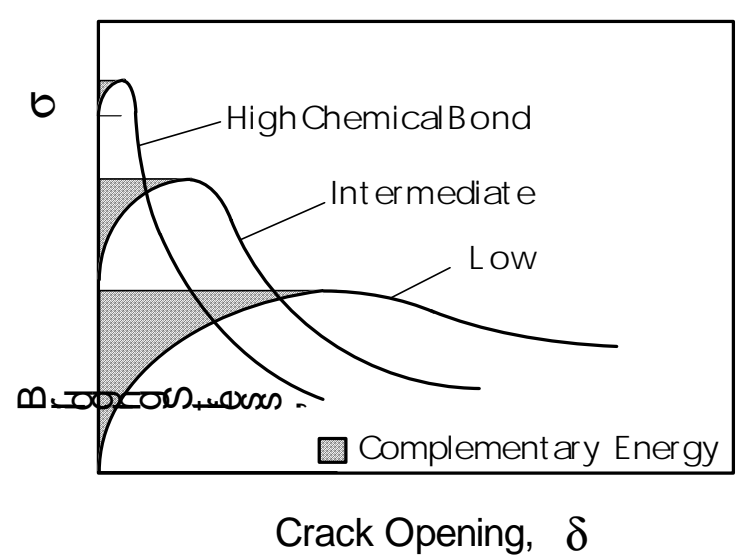

Fig. 8: Schematics of $\sigma-\delta$ Curves for Fibers With Different Degrees of Chemical Bond

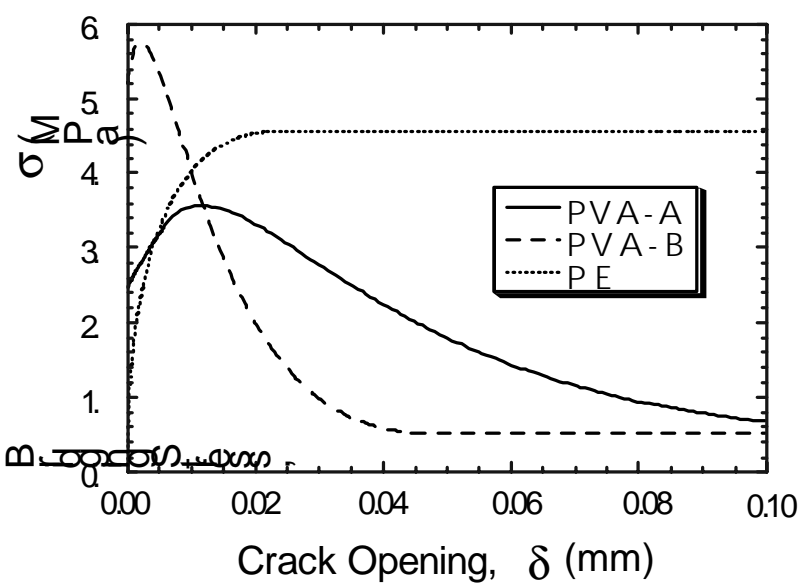

Fig. 9: Computed $\sigma-\delta$ Relations for the Three Composites

\section{COMPLEMENTARY ENERGY OF SEVERAL COMPOSITES}

We consider now the $\sigma-\delta$ relation and complementary energy of three cement based composites. In addition to the two composites with PVA-A and PE fibers already introduced, we add a third composite here - a PVA-B with similar interface properties as PVA-A, but with different fiber 
diameter and strength. The specific mechanical and geometric properties of PVA-B fiber have also been collected in Table 1.

Table 2 shows the interfacial properties measured from single fiber pull-out tests [12,13] of these three composites. For the PVA fibers, the pull-out test load-deformation curves show a sudden drop at peak pull-out load, which is used to calibrate the interfacial fracture energy. The fiber strength reduction factor $\mathrm{f}$ ' is used to reflect lower apparent strength of PVA fibers observed in inclined pull-to-rupture tests [14].

The $\sigma-\delta$ relations for the three composites are shown in Fig. 9, based on the high end of the $\mathrm{G}_{\mathrm{d}}$ value $\left(6 \mathrm{~J} / \mathrm{m}^{2}\right)$. The range of $\mathrm{G}_{\mathrm{d}}$ value is due to the variation in the single fiber pull-out data. The corresponding complementary energy $\mathrm{C}$ is tabulated in Table 2. For the composites with PVA-B and PE fibers, the cementitious matrices have similar $\mathrm{w} / \mathrm{c}$ ratio of $0.27, \mathrm{E}_{\mathrm{m}}=23 \mathrm{GPa}$, and $\mathrm{J}_{\mathrm{o}}=2-4.7$ $\mathrm{J} / \mathrm{m}^{2}$ from uniaxial and fracture tests of the matrix. The matrix for the composite with PVA-A fiber has a higher w/c ratio of 0.47 and the $\mathrm{J}_{\mathrm{o}}$ value may be expected to be less than the indicated range. Equation (1) and the values of $\mathrm{C}$ in the last row of Table 2 therefore provide a clear explanation why the composites with PVA-A and PE fibers satisfy the steady state cracking criteria, and therefore can be expected to show tensile strain-hardening and to exhibit damage tolerant behavior as described in Section 2 above. In contrast, the composite with PVA-B cannot be expected to show damage tolerant behavior. Indeed, this composite shows very marginal strain-hardening response under uniaxial tensile loading, with only a few widely spaced multiple cracks. The strain capacities of the three composites are also included in Table 2.

It should be noted that even with the PVA-B fiber, damage tolerance could be designed by lowering the $\mathrm{J}_{\mathrm{o}}$ and interface chemical bond via control of the matrix design. Indeed ductile indentation behavior similar to that shown in Fig. 1 has been demonstrated with PVA-B fiber by this route.

Table 2: Interface and Composite Properties

\begin{tabular}{|c|c|c|c|}
\hline & PVA-A & PVA-B & PE \\
\hline Interfacial Toughness $\left(\mathrm{J} / \mathrm{m}^{2}\right)$ & $3.0-6.0$ & $3.0-6.0$ & 0.0 \\
\hline Interfacial Friction (MPa) & 2.0 & 3.0 & 0.7 \\
\hline Snubbing Coefficient f & 0.5 & 0.5 & 0.8 \\
\hline Fiber Strength Reduction Factor $\mathrm{f}^{\prime}$ & 0.3 & 0.3 & 0.0 \\
\hline Fiber Volume Fraction (\%) & 2 & 1.5 & 2 \\
\hline Water/Cement Ratio & 0.47 & 0.27 & 0.27 \\
\hline Tensile Strain Capacity (\%) & 1.2 & 0.22 & 5.5 \\
\hline $\mathbf{J}_{\mathbf{0}}\left(\mathbf{J} / \mathbf{m}^{2}\right)$ & $2-4.7$ & $2-4.7$ & $2-4.7$ \\
\hline Complementary Energy C $\left(\mathrm{J} / \mathrm{m}^{2}\right)$ & $4.5-8.9$ & $0.3-2.7$ & 17.4 \\
\hline
\end{tabular}

\section{CONCLUSIONS}

1. Chemical interfacial bond reduces the complementary energy in crack bridging behavior of composites in comparison with those with only interfacial friction, and may therefore lead to the vanishing of damage tolerant behavior. This is illustrated by comparing the mechanical behavior of the PE composite and the PVA-B composite. 
2. Even in the presence of chemical bond, proper combination of fiber, matrix and interface properties can still lead to a $\sigma-\delta$ relation which has sufficient complementary energy to cause steady state cracking, and damage tolerant response. This is demonstrated with the composite using PVA-A fiber.

3. Design of damage tolerant composites for structural applications can be conducted on a rational basis making use of steady state crack mechanics and micromechanical modeling of the $\sigma-\delta$ relation. The availability of $\sigma-\delta$ relation models for a variety of fiber properties and interfacial characteristics $[12,14-17]$ provides a foundation for composite design with a variety of fiber types.

4. The linkage between interfacial characteristics and composite damage tolerant properties provides guidelines for tailoring the interface of a given fiber for desirable composite behavior.

\section{ACKNOWLEDGMENTS}

This research has been completed when the first author was a Visiting Professor at the Hong Kong University of Science and Technology, on sabbatical leave from the University of Michigan, Ann Arbor. Support by the Department of Civil and Structures Department at the HKUST is gratefully acknowledged. Part of the research work is supported by the National Science Foundation (Grant NSF-EQ CMS-9601262) to the University of Michigan.

\section{REFERENCES}

1. Li, V.C, in Proc. 9th ICF Conference on Fracture, Sydney, Australia, Ed. B.L.Karihaloo, Y.W. Mai, M.I. Ripley and R.O. Ritchie, Pub. Pergamon, UK, (1997) pp. 619-630.

2. Maalej, M. and V.C. Li, American Concrete Institute Structural J., 92[2] (1995) 167-176, 1995.

3. Li, V.C., "Engineered Cementitious Composites - Tailored Composites Through Micromechanical Modeling," to appear in Fiber Reinforced Concrete: Present and the Future, Eds: N. Banthia, A. Bentur, and A. Mufti, Canadian Society of Civil Engineers (1997).

4. Kabele, P., V.C. Li, H. Horii, T. Kanda and S. Takeuchi, in Proc. of 5th International Symposium on Brittle Matrix Composites (BMC-5), Warsaw, Poland (1997).

5. Kanda, T., Watanabe, S. and V.C. Li, "Shear Behavior of Bolt Joint for High Performance Fiber Reinforced Mortar Panels, " in preparation (1997).

6. Marshall, D. and Cox, B.N., Mechanics of Materials 7 (1988) 127-133.

7. Maalej, M., T. Hashida, and V.C. Li, J. Amer. Ceramics Soc., 78 [12] (1995) 3369-3375.

8. Li, V.C. and T. Hashida, J. of Materials Science Letters, 12 (1993) 898-901.

9. Kabele, P., Horii, H., J. Materials, Conc. Struct., Pavements, (Proc. of JSCE No. 532/V-30), (1996) 209-219.

10. Aveston, J., Cooper, G. A. and Kelly, A. In The Properties of Fiber Composites, Conf. Proc. National Physical Lab., IPC Science and Technology Press, Surrey, England (1971) pp.15-26.

11. Li, V.C. and Leung, C.K.Y., ASCE J. of Engineering Mechanics, 118[11] (1992) 2246-2264.

12. Lin, Z., T. Kanda, and V.C. Li, "On Interface Characterization and Performance of Fiberreinforced Cementitious Composites," in preparation (1997).

13. Li, V. C., Mishra, D. K., Wu, H. C., Materials and Structures, RILEM 28 (1995) 586-595.

14. Kanda, T. and V.C. Li, "Interface Property and Apparent Strength of a High Strength Hydrophilic Fiber in Cement Matrix," Accepted for publication in ASCE J. Materials in Civil Engineering (1997). 
15. Li, V.C. and K. Obla, Composites Engineering International Journal Part B 27B, (1996) 275284.

16. Maalej, M., V.C. Li, and T. Hashida, ASCE J. Engineering Mechanics, 121[8] (1995) 903-913.

17. Li, V.C. and K.H. Obla, Int'l J. of Composites Engineering, 4[9] (1994) 947 - 964. 